Perspectiva Geográfica

ISSN 0123-3769 (Impreso) - 2500-8684 (En línea)

Vol. 21 N. ${ }^{\circ} 2$ de 2016

Julio - Diciembre

pp. 225-250

\title{
Propuesta metodológica para la gestión de los paisajes de páramo en el marco de la Iniciativa Latinoamericana del Paisaje (LALI)
}

\author{
Methodological Proposal for the Management of Paramo \\ Landscapes Under the Latin American Landscape Initiative \\ (LALI)
}

\section{Diego Andrés Muñoz Guerrero' ${ }^{1}$ José Gómez Zotano²}

Para citar este artículo utilice el nombre completo así:

Muñoz, D. y Gómez-Zotano, J. (2016). Propuesta metodológica para la gestión de los paisajes de páramo en el marco de la Iniciativa Latinoamericana del Paisaje (LALI). Perspectiva Geográfica, 21(2), 225-250. doi: 10.19053/01233769.5850

\section{Resumen}

La presente investigación propone una metodología que permita la implementación de la Iniciativa Latinoamericana del Paisaje en los páramos de Colombia. La propuesta retomó y adaptó algunos aspectos de otras metodologías y para su calibración, se aplicó a tres páramos en el sur de

1 Ingeniero Agroforestal de la Universidad de Nariño, Magister en Agroforestería Tropical del Centro Agronómico Tropical de Investigación y Enseñanza (CATIE) de Costa Rica, Candidato a Doctor en Geografía del Instituto Geográfico Agustín Codazzi en convenio con la Universidad Pedagógica y Tecnológica de Colombia (UPTC). Profesor Asistente, Universidad de Nariño.damg30@hotmail.com

2 Profesor titular de Geografía Física del departamento de Análisis Geográfico Regional y Geografía Física de la Universidad de Granada. jgzotano@ugr.es 
Colombia: Galeras, Paja Blanca y Chiles (Departamento de Nariño). Dicha propuesta se articula en las siguientes etapas: (a) identificación de los paisajes; (b) análisis de las transformaciones paisajísticas en los últimos años; (c) simulación prospectiva del paisaje; (d) cualificación del paisaje; y (e) políticas o propuestas de gestión paisajística. Los resultados del método permitieron establecer de manera integral las principales actuaciones paisajísticas necesarias, acordes a las características actuales de los paisajes de páramo, a su comportamiento histórico, sus tendencias futuras y sobre todo a las preferencias de la comunidad.

Palabras clave: paisaje, páramo, patrimonio cultural, planificación sostenible, valor paisajístico.

\begin{abstract}
This research proposes a methodology for the implementation of the LALI on the Paramos of Colombia. The proposal retook and adapted some aspects of other methodologies. For its calibration it was applied to three paramos in southern Colombia: Galeras, Paja Blanca and Chiles (Department of Nariño). This proposal is structured in the following stages: (a) Identification of landscapes. (b) Analysis of landscape transformations in recent years. (c) Prospective simulation of landscape. (d) Qualification of landscape. (e) Policies or landscape management proposals. The results of the method allowed us to establish holistically major scenic necessary actions, according to the current characteristics of the paramo landscapes such as its historical relevance, future trends and above all the preferences of community.
\end{abstract}

Keywords: cultural heritage, landscape, landscape value, paramo, sustainable planning. 


\section{Introducción}

En el ámbito internacional, en los últimos tiempos ha venido tomando auge la formulación y concertación de políticas para promover el reconocimiento, la valoración y la planificación sostenible del paisaje, mediante la adopción de convenios que reconozcan su diversidad, valores locales, regionales y nacionales, tanto tangibles como intangibles, así como los principios y procesos pertinentes para salvaguardarlo. Ejemplo de ello son la Convención Europea del Paisaje (CEP) (Consejo de Europa, 2000), la Iniciativa Latinoamericana del Paisaje (LALI) (Federación Internacional de Arquitectos Paisajistas, 2012), y en el caso de Colombia la Carta Colombiana del Paisaje (SAP, 2010) que se firmó en el año 2012. Estas políticas están encaminadas a tomar medidas generales de reconocimiento de los paisajes; de definición y caracterización; de aplicación de políticas para su protección y gestión; de participación pública y de integración de los paisajes en las políticas de ordenación del territorio, así como en las políticas económicas, sociales, culturales y ambientales.
La Iniciativa Latinoamericana del Paisaje (LALI) se firmó en Colombia por 12 países, con el objetivo de promover el reconocimiento, la valoración, la protección, la planificación y la gestión sostenible del paisaje latinoamericano. Específicamente para Colombia, basados en esta iniciativa, la Sociedad Colombiana de Arquitectos Paisajistas (SAP) y sus miembros plantearon la Carta Colombiana del Paisaje. La LALI y la Carta Colombiana del Paisaje no establecen métodos concretos para abordar dichos enfoques, lo que hace necesario ahondar en metodologías que sirvan como herramientas que permitan avanzar hacia el reconocimiento jurídico de los paisajes.

Ante lo dicho, este artículo propone una nueva metodología retomando algunos aspectos de experiencias aplicadas en otros ámbitos. Para ello, se tomó como ejemplo de trabajo o de aplicabilidad uno de los paisajes más característicos y amenazados de la región Andina colombiana, como son los páramos. Sus paisajes, a pesar de los reconocidos procesos de afectación antrópica que vienen sufriendo, sostienen una gran diversidad biológica y cultural. Muchos de ellos poseen una gran importancia para las co- 
munidades locales, así como también infunden respeto y afecto, refuerzan la identidad cultural y son esenciales para el bienestar espiritual. Al respecto, Mallarach (2008) sostiene que, a diferencia de otros valores como la biodiversidad o los servicios ecosistémicos que están relacionados, los paisajes paramunos, los valores culturales, estéticos y espirituales son fundamentales en el más estricto sentido de la palabra. Por lo tanto, reconocer y salvaguardar la integridad de esta interacción tradicional es esencial para la protección, la conservación y el desarrollo de dichas áreas.

Se abordó la metodología específicamente propuesta para los páramos de Galeras, Paja Blanca y Chiles del departamento de Nariño, Colombia, los cuales son de mucha importancia para la comunidad nariñense por sus diversos valores ecológicos y socioculturales. En este sentido, el objetivo principal de este trabajo es generar una propuesta metodológica que permita la implementación de la Iniciativa Latinoamericana del Paisaje (LALI) en los paisajes de páramos. Se parte de la hipótesis general de que los ambientes paramunos poseen diversos paisajes, donde sus condiciones biofísicas y la estrecha relación ser humano-naturaleza acarrean un sinnúmero de valores tanto ecológicos como socioculturales que le dan una propia estructura funcional del territorio, formando un todo que se desarrolla y evoluciona.

\section{2. Área de estudio}

La metodología se aplicó en los páramos Chiles, Galeras y Paja Blanca (departamento de Nariño, Colombia). El páramo Galeras hace parte del Parque Nacional Santuario de Flora y Fauna Galeras (SFFG), declarado como tal en marzo de 1985; tiene un área de 8.866 ha, y se ubica en las confluencias de las cordilleras central y occidental, extremo sur-occidental del departamento de Nariño: entre las coordenadas $1^{\circ} 09^{\prime}-1^{\circ} 15^{\prime}$ de latitud norte y $77^{\circ} 19^{\prime}-77^{\circ} 26^{\prime}$ de longitud oeste.

El Páramo de Paja Blanca tiene un área de 4.647 ha, y fue declarado Parque Natural Regional en el año 2015, se ubica en el departamento de Nariño en la parte central del nudo de los Pastos: entre las coordenadas $0^{\circ} 50^{\prime}-1^{\circ} 06^{\prime}$ de latitud norte y $77^{\circ} 45^{\prime}-77^{\circ} 25^{\prime}$ de longitud oeste, con una distribución 
altitudinal entre los 3.000 y 3.600 m.s.n.m.

El páramo de Chiles se encuentra ubicado en el municipio de Cumbal, departamento de Nariño: entre las coordenadas $0^{\circ} 41^{\prime}-0^{\circ} 57^{\prime}$ de latitud norte y $77^{\circ} 53^{\prime}-77^{\circ} 59^{\prime}$ de longitud oeste, además, el páramo de Chiles cubre una extensión de 5.171 ha. No obstante, para efectos de su plan de manejo el Instituto de Investigación de Recursos Biológicos Alexander Von Humboldt (IAvH, 2009) delimitó como área de influencia 11.314 ha, correspondientes a toda el área del Resguardo de Chiles (Figura 1).
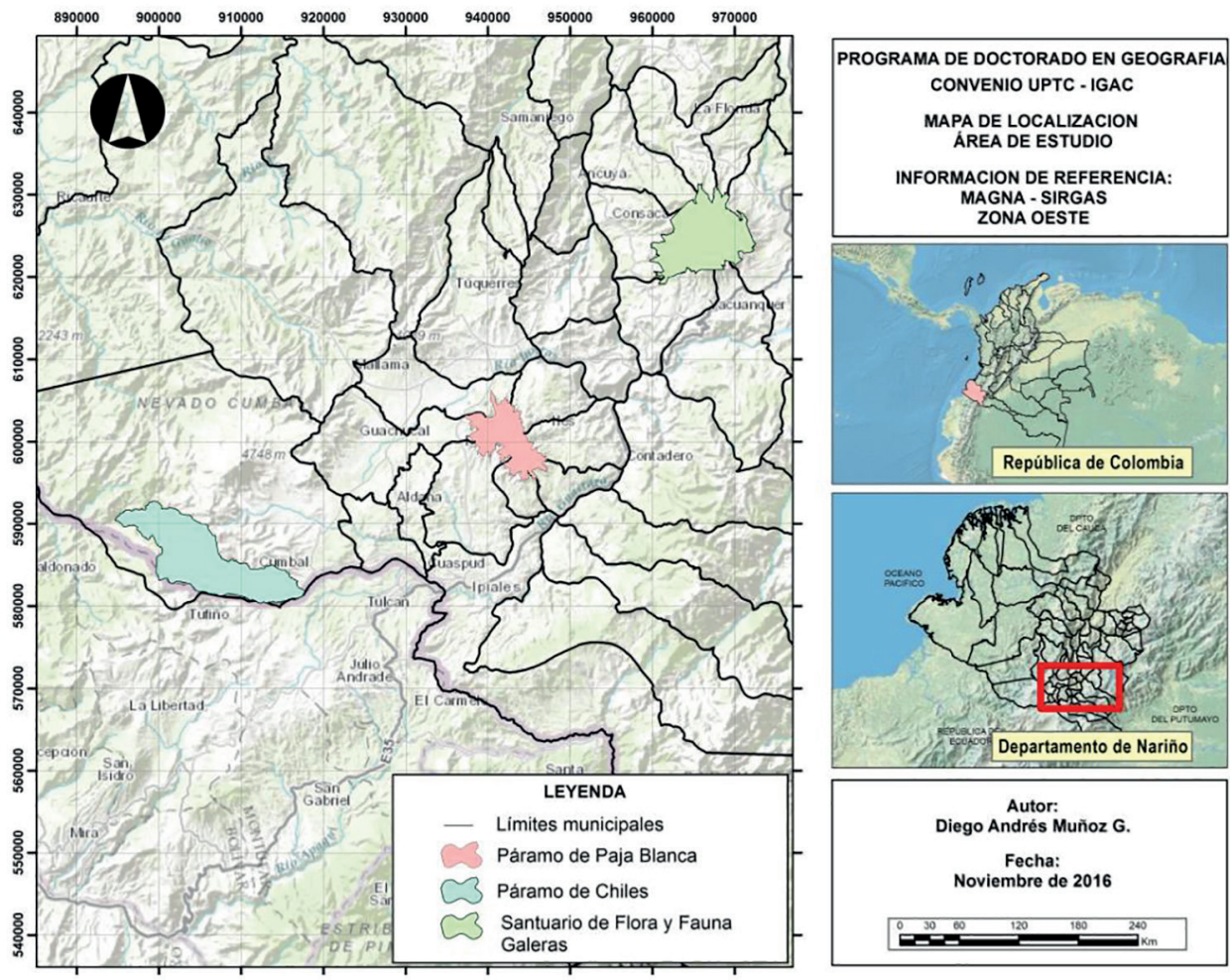

Figura 1. Localización área de estudio

Fuente: Elaboración propia. 


\section{Metodología}

\section{a. Identificación y delimitación}

Esta etapa está basada en el enfoque metodológico de Estimación del Carácter Paisajístico (LCA por sus siglas en inglés) (Gómez y Riesco, 2010). Se partió de un estudio de los fundamentos naturales del paisaje como son: relieve, suelos, clima, hidrología, bioclima, vegetación potencial y hábitat faunístico potencial, para determinar con los geosistemas potenciales que según Gómez-Zotano (2003) corresponden a unidades ecogeográficas equipotenciales previas a la intervención antrópica. Para ello, se tomó como punto de partida los mapas geomorfológicos y climáticos, ya que marcan la transición de uno potencial ecológico a otros. Posteriormente, se superpuso el mapa hidrológico y seguidamente el bioclimático para establecer nuevas divisiones. Finalmente se realizó un análisis de coincidencias para obtener los geosistemas potenciales con las siguientes variables: vegetación potencial, hábitat faunístico y suelo.

Se cruzó el mapa de geosistemas potenciales con los usos y coberturas del suelo, tipos de asenta- mientos, explotaciones vigentes, presiones y dinámicas. De la combinación de esta información, se obtuvo el mapa de geosistemas potenciales modificados. En segundo lugar, se introdujo la variable visual, cruzando el mapa de geosistemas potenciales modificados con mapas de visibilidad, y además se añadió el modelo digital del terreno de tal forma que permita visualizar las grandes diferencias topográficas en cada ámbito de estudio, y por ende, facilitar la identificación de nuevas discontinuidades espaciales (valles, montañas, cañones, etc.).

Los paisajes resultantes se subdividieron en áreas distintivas y singulares, reconocibles y dotadas de un carácter paisajístico común (Áreas), para posteriormente agruparlas en función de rasgos paisajísticos compartidos en una tipología básica de paisajes (tipos). De estos tipos, se desprenden otras Áreas de Nivel III. Las denominaciones de los tipos de paisaje se hicieron teniendo en cuenta términos que reflejen las influencias o factores dominantes en el paisaje como el relieve, los usos y los asentamientos. Las denominaciones de las áreas se realizaron de acuerdo a topónimos concretos, tanto si alu- 
den a hechos de base natural como antrópica.

\section{b. Transformación}

Con el propósito de tener un conocimiento sobre la dinámica $\mathrm{y}$ estado de evolución de cada paisaje delimitado (Áreas Nivel III), se analizaron las transformaciones paisajísticas ocurridas en cada páramo en el periodo 1984-2013, así como las principales variables socioeconómicas y biofísicas que pudieron tener relación con dichas transformaciones. Para ello, se realizó un análisis multitemporal aplicando la metodología de clasificación supervisada (Castleman, 1996), el cual se efectuó a través de la interpretación de imágenes satelitales Landsat del año 1984 e imágenes Aster del año 2013. Las imágenes fueron sometidas a tratamientos de calibración y ajuste tanto geométrico, radiométrico, atmosférico y topográfico. La clasificación de las categorías de uso se efectuó teniendo en cuenta la metodología Corine Land Cover. Todo el proceso de interpretación de imágenes se realizó en el programa Erdas Imagine 2013, y la vectorización y producción final de los mapas de coberturas se realizó en el programa ArcGIS 10.2.
Como paso último, se realizó una intersección cartográfica con las áreas de paisaje de Nivel III para poder analizar las permanencias y transformaciones de cada paisaje ocurridas en el periodo analizado.

Para el análisis de los factores más importantes que han influido en las transformaciones de las Áreas de Nivel III de los últimos 29 años se analizaron los factores demográficos para determinar las tendencias de crecimiento. Además, se generaron mapas de densidad poblacional para establecer relaciones con la disposición espacial de las coberturas, la cual se evaluó con el estadístico Cramer's $V$. Sus valores varían entre 0 y 1 : un valor de 0 implica independencia de los atributos y un valor de 1 denota asociación perfecta (Eastman, 2006).

También se realizaron distancias euclidianas y regresiones logísticas, con el fin de descubrir la relación entre la estructura vial y las viviendas con las áreas que se transformaron durante los años 1984 y 2013. El estadístico utilizado para evaluar el modelo de regresión, fue el Relative Operating Charasteric (ROC). Todo el proceso se realizó con el módulo Logisticreg del programa Idrisi Selva. 
Al igual que las variables socioeconómicas, también se hicieron regresiones logísticas para encontrar relaciones entre algunas variables físico-bióticas y las transformaciones presentadas en el periodo 1984-2013. Las variables que se escogieron fueron: el relieve, las pendientes y la distancia a los ríos.

\section{c. Simulación}

Esta propuesta considera que se debe también analizar las tendencias futuras de cada Área de paisaje de Nivel III, cuyos resultados son importantes para establecer grados de prioridad en la gestión de cada paisaje en las etapas posteriores del presente método.

La simulación de los paisajes de páramo para los próximos 30 años se realizó con base al enfoque de Redes Neuronales Artificiales (RNAs) (Isasi y Galván, 2004), las cuales son estructuras de mapeo no lineal basadas en el funcionamiento del cerebro humano. Se utilizó para ello, el módulo Land Change Modeler (LCM) que viene incorporado en el programa Idrisi Selva. Dicho enfoque requirió efectuar los siguientes pasos: (a) la selección y análisis de variables de transición; (b) la identificación de las transicio- nes potenciales y (c) la estimación de la cantidad de cambio y localización de los cambios. Después de obtener las matrices de transición de cada categoría de cobertura, el módulo LCM de Idrisi, a través de tablas y mapas, predice los cambios para los próximos 30 años (estimados hasta el año 2042). Con la cartografía de cambios proyectados, se hizo una intersección con los mapas de áreas de paisaje de Nivel III para estimar de manera cuantitativa los cambios en coberturas que cada paisaje podría experimentar.

\section{d. Cualificación}

El presente método propone realizar una estimación del valor y significancia de los paisajes previamente identificados (Áreas de Nivel III) desde el punto de vista de la ecología, productividad, historia, patrimonio, uso social, mitología, espiritualidad y simbología. Esta valoración fue hecha de manera objetiva por los investigadores a partir de revisión de literatura, e información de campo. Asimismo, se propone realizar una valoración directa de tipo subjetiva (Aramburu et al., 2006): se toman dos o tres fotografías de cada paisaje con el propósito de que las comunidades las califiquen de acuerdo con una 
lista de valores o adjetivos (Craik, 1975). Estos adjetivos pueden establecerse de acuerdo a las características culturales y vocabulario dominantes en la zona (para este caso, el departamento de Nariño). En total se definieron 30 adjetivos similares a los usados por Muñoz-Pedreros et al. (1993). Los adjetivos son clasificados en seis categorías: (1) feo, (2) sin interés, (3) agradable, (4) distinguido, (5) fantástico y (6) espectacular; a cada adjetivo le corresponde un valor según la escala internacional de valores de paisaje propuesta por Fines (1968).

Para su aplicabilidad se realizó una encuesta estructurada que recogió algunos datos del entrevistado como: edad, sexo, lugar de habitación y ocupación. Esta encuesta estuvo formada por dos imágenes de $10 \mathrm{~cm}$ x $15 \mathrm{~cm}$ de las áreas de paisaje seleccionadas, y estaba acompañada de los adjetivos calificativos que se determinaron. Entre las preguntas, también se preguntó qué tipo de acción recomendaría para el paisaje observado (Conservación, Protección, Restauración o Mejoramiento). Cada entrevistado evaluó de forma rápida las imágenes, seleccionando según su criterio el adjetivo que califica a la fotografía observada. Para la se- lección de la muestra se aplicó la metodología del muestreo teórico propuesto por Glasser y Strauss (1967), donde de manera intencional se seleccionaron personas con diferentes ocupaciones, entre ellas: campesinos que habitan en los páramos, estudiantes, técnicos y profesionales, entre otros.

Para los tres ámbitos estudiados se conformó una muestra total de 400 personas, que corresponde a un número mayor al recomendado por algunos autores como Brown y Daniel (1986), Paquet y Bélanger (1997), Muñoz-Pedreros et al. (2000). Las respuestas fueron analizadas mediante técnicas estadísticas como las frecuencias y el análisis de varianza. En las áreas de paisaje (Nivel III) analizadas se determinó cuál fue el adjetivo de mayor frecuencia. Asimismo, se efectuó un análisis de varianza para establecer si hubo influencia o no del sexo, ocupación y edad de los entrevistados con respecto a las valoraciones obtenidas.

El método antes descrito aplica para cada una de las áreas de paisaje, pero como ejemplo práctico, en este estudio solamente se escogieron tres paisajes (uno en cada páramo) o Áreas de Nivel III. 


\section{e. Políticas}

Las etapas anteriores se articulan en esta última etapa que corresponde a un establecimiento de directrices de actuación para la protección, gestión y ordenación del paisaje. Lo anterior mantiene un interés por proteger aquellos elementos que presentan valores ecológicos, estéticos y culturales; orientar su gestión cotidiana manteniendo sus valores; o bien proponer la restauración de paisajes degradados o en peligro de degradación conforme a su tendencia y proyección futura. Los objetivos de calidad paisajística son el punto de encuentro entre las aspiraciones de la ciudadanía, la opinión de los expertos y las políticas públicas en relación al paisaje, estos reflejan la meta final que la población se marca a sí misma en términos de mejora de sus paisajes. Todos los objetivos corresponden a las aspiraciones de las poblaciones en lo concerniente a las características de su marco vital una vez hayan conocido su estado, valores y riesgos. En primer lugar, se realizó un diagnóstico del paisaje atendiendo a sus características biofísicas, ecoculturales, funcionales, de transformación y tendencias. Posteriormente, se han establecido una serie de recomen- daciones u objetivos para la intervención paisajística.

Para la formulación de dichos objetivos de calidad paisajística, se tuvo en cuenta las áreas de paisaje de Nivel III, los resultados del proceso de transformación y simulación, y su valoración. De la misma forma se tomó en cuenta la percepción de la comunidad sobre lo que desean de sus paisajes, datos que fueron recolectados en campo a través de 400 encuestas aplicadas en los tres ámbitos anexos al proceso de valoración anterior.

\section{Resultados y discusión}

\subsection{Identificación y delimitación}

El método propuesto permitió definir múltiples niveles de unidades paisajísticas. Cada ámbito fue considerado como un Área de paisaje de Nivel I, de los cuales se subdividieron en Tipos (Nivel II). Algunos tipos se agruparon de acuerdo a las características de relieve y de coberturas del suelo (Tabla 1). Los tipos de paisaje de Nivel II corresponden a un nivel de mayor detalle, donde es primordial que se resalten las características morfoestructurales, climáticas y biogeográficas, además de la vegetación y el uso 
del suelo. A un nivel mucho más grande de detalle (Nivel III), el método identificó y delimitó un total de 64 áreas de paisaje. Se delimitaron más áreas de paisaje en Paja Blanca que en Chiles y Galeras, esto se debe a que en presencia de una mayor sectorización, el méto- do exige que se reconozcan algunas áreas como unidades paisajísticas (ampliamente reconocidas por sus comunidades): su división política $\mathrm{y}$ algunas toponimias específicas como lomas, cerros, entre otros, como en el caso de Paja Blanca.

Tabla 1. Áreas y tipos de paisajes en los páramos de Chiles, Galeras y Paja Blanca

\begin{tabular}{|c|c|c|}
\hline \begin{tabular}{|c|} 
ÁREA \\
(Nivel I)
\end{tabular} & TIPOS (Nivel II) & AREAS (Nivel III) \\
\hline \multirow{2}{*}{$\begin{array}{l}\text { Páramo } \\
\text { de } \\
\text { Chiles }\end{array}$} & $\begin{array}{l}\text { Cumbres y laderas volcánicas } \\
\text { con páramo, glaciares, bosque } \\
\text { natural denso y fragmentado }\end{array}$ & $\begin{array}{l}\text { Cerro Canguil, volcán Cerro Negro, cráter volcán Cerro } \\
\text { Negro, cráter volcán Chiles y volcán Chiles. }\end{array}$ \\
\hline & $\begin{array}{l}\text { Laderas altoandinas volcánicas } \\
\text { con pastos, cultivo y bosque } \\
\text { natural fragmentado y tejido } \\
\text { urbano continúo. }\end{array}$ & $\begin{array}{l}\text { Chiles, Casco urbano resguardo Chiles, La Calera y } \\
\text { Nazate. }\end{array}$ \\
\hline \multirow{3}{*}{$\begin{array}{l}\text { Páramo } \\
\text { de Paja } \\
\text { Blanca }\end{array}$} & \multirow{2}{*}{$\begin{array}{l}\text { Cumbres y laderas volcánicas } \\
\text { con páramo, bosque natural } \\
\text { denso y fragmentado. }\end{array}$} & $\begin{array}{l}\text { Loma Paja Blanca, loma Imbula Grande, cerro Las } \\
\text { Cruces, cerro Campana, loma Redonda, loma El } \\
\text { caliente, loma El Pailón, loma El mirador, Imbula } \\
\text { grande, El Carmen-Chorrera Negra-Los Cedros, loma } \\
\text { Gorgona. }\end{array}$ \\
\hline & & $\begin{array}{l}\text { San José de Chillanquer, Casa Fría, Chires mirador } \\
\text { Piacun-Imbula Chico, Chorrera Negra, El Comun- } \\
\text { VillaSur, La Campana, El Gualte, Villanueva. }\end{array}$ \\
\hline & $\begin{array}{l}\text { Laderas andinas volcánicas con } \\
\text { mosaico de pastos y cultivos. }\end{array}$ & $\begin{array}{l}\text { La Campana, Villa del Sur-Gavilanes-Los Monos- } \\
\text { La Campana, Villa Nueva, Las Guacas, San José, } \\
\text { El Gualte, San José de Chillanquer, Chires Mirador, } \\
\text { Imbula Grande, El Mirador, El Común-Imbula Chico, } \\
\text { Imbula Grande-Chorrera Negra, Chorrera Negra, Santo } \\
\text { Domingo, Dos caminos, Pilispí, El Carmen El Común. }\end{array}$ \\
\hline \multirow{4}{*}{$\begin{array}{l}\text { Páramo } \\
\text { de } \\
\text { Galeras }\end{array}$} & $\begin{array}{l}\text { Cumbres volcánicas con } \\
\text { páramo. }\end{array}$ & Anfiteatro Volcán Galeras, Cráter Volcán Galeras. \\
\hline & $\begin{array}{l}\text { Laderas volcánicas abruptas } \\
\text { con páramo y bosque natural } \\
\text { denso y fragmentado. }\end{array}$ & $\begin{array}{l}\text { Loma de Telpis, Cuchilla Rumichaca, Telpis, Alto } \\
\text { Bomboná-San José, Cuchilla Ciénaga Grande, } \\
\text { Microcuenca del río Azufral, Laguna Negra, Urcunina, } \\
\text { Churupamba-Santa Bárbara, El Barranco-El Chorrillo. }\end{array}$ \\
\hline & $\begin{array}{l}\text { Laderas volcánicas abruptas } \\
\text { con pastos y cultivos. }\end{array}$ & Santa Bárbara, El Chorrillo \\
\hline & $\begin{array}{l}\text { Laderas volcánicas empinadas } \\
\text { con páramo, bosque natural } \\
\text { denso y fragmentado. }\end{array}$ & $\begin{array}{l}\text { El Barranco, Microcuenca río Zaragoza, Cuchilla } \\
\text { Ciénaga Chiquita, San José. }\end{array}$ \\
\hline
\end{tabular}

Fuente: Elaboración propia. 


\subsection{Transformación de los paisa- jes en el periodo 1984-2013}

Organizar las áreas de paisaje de Nivel III en una matriz donde las filas corresponden a los paisajes y las columnas a las persistencias y transformaciones en el periodo analizado (Tabla 2), es bastante práctico y útil para determinar el grado de afectación de cada Área de paisaje. En la Tabla 2 se observa que las áreas de paisaje Cerro Cangüil y Volcán Chiles, son paisajes en un estado bastante crítico pues en 29 años se han transformado un total de 419 ha y 99 ha respectivamente. Lo mismo sucede con los paisajes Microcuenca del río Azufral y Churupamba-Santa Bárbara en el páramo de Galeras; y los paisajes Loma Paja Blanca, Imbula Grande, El Carmen-El Común, San José de Chillanquer-Casa Fría-Chires mirador-Piacun-Imbula Chico en el páramo de Paja Blanca (Tabla 3).

Se puede establecer de manera general que en el páramo de Chiles fue donde más se presentó una perturbación y deforestación de bosques naturales y coberturas de páramo. La densidad poblacional estuvo relacionada con los cambios de coberturas de páramo y de bosque natural fragmentado, experimenta- dos en el páramo Galeras. En Chiles, esta variable estuvo relacionada con los cambios de mosaico de pastos y cultivos, y tejido urbano continuo. En Paja Blanca (Tabla 3) no se observó relación alguna, resultados similares fueron encontrados por Bonilla (1985), Hartshorn (1983), Pérez y Protti, (1978). Para la distancia a las viviendas, se encontraron coeficientes ROC positivos para los tres páramos, lo que indica que las transformaciones del paisaje no se dan necesariamente en zonas cercanas a las viviendas. Los modelos de regresión presentaron buenos ajustes, especialmente en Paja Blanca. Las regresiones logísticas entre las variables áreas transformadas y la distancia a las vías, mostraron coeficientes negativos en Chiles y Paja Blanca, indicando mayores transformaciones en áreas cercanas a las vías. Por otro lado, en Galeras no se presentan transformaciones en áreas cercanas a las vías. 


\begin{tabular}{|c|c|c|c|c|c|c|c|c|c|c|c|c|}
\hline & 急 & $\begin{array}{l}0 \\
2 \\
2\end{array}$ & $\begin{array}{l}+ \\
\dot{\infty} \\
+\end{array}$ & $\vec{\gamma}$ & $\stackrel{+}{\stackrel{+}{\sim}}$ & & & & & & & $\widehat{\sigma}$ \\
\hline & 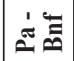 & & & & & & & & & & & 0 \\
\hline$\stackrel{m}{\vec{T}}$ & 跑 & \pm & & $\Xi$ & & & & & & & & 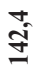 \\
\hline 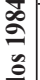 & 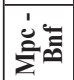 & & & & & & & & & & & 0 \\
\hline 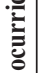 & 它司 & & & 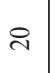 & & & & & & & & ㄱ \\
\hline .气 & 咅苛 & & & & & & & & & & & 0 \\
\hline $\begin{array}{l}0 \\
\ddot{y} \\
\ddot{z}\end{array}$ & 思 & & & के & & & & & & & & $\tilde{\Omega}$ \\
\hline 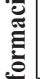 & تَّ & $\begin{array}{l}0 \\
\approx \\
\approx\end{array}$ & & & & & & & & & & $\begin{array}{l}0 \\
\ddot{2}\end{array}$ \\
\hline ב̂. & 总芯 & $\vec{a}$ & $\overrightarrow{0}$ & $\stackrel{?}{\Xi}$ & $\bar{\infty}$ & & & & & & & ले \\
\hline & 㤩 & 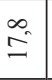 & & $\vec{n}$ & & & & & & & & ते \\
\hline & 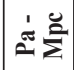 & $\hat{i}$ & $\stackrel{m}{ \pm}$ & & $\hat{n}$ & & & & & & & $\hat{\tilde{g}}$ \\
\hline & 플 & $\underset{m}{\stackrel{2}{2}}$ & $\begin{array}{l}\vec{f} \\
\hat{n}\end{array}$ & $\begin{array}{l}\text { त̃ } \\
\text { त्र్ల }\end{array}$ & 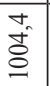 & $\begin{array}{l}\text { है } \\
\text { कू }\end{array}$ & $\hat{\infty}$ & \begin{tabular}{l} 
? \\
\multirow{\infty}{*}{}
\end{tabular} & 导 & $\hat{\tilde{\Xi}}$ & $\stackrel{m}{a}$ & $\begin{array}{l}\frac{1}{0} \\
\stackrel{0}{\sigma}\end{array}$ \\
\hline \multirow{7}{*}{ 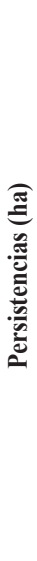 } & ש & & & $\stackrel{\vec{c}}{\unlhd}$ & & & & & & & & $\simeq$ \\
\hline & $\cong$ & & & & & & & & & & 9 & 2 \\
\hline & No & $\stackrel{+}{m}$ & & & & & & $\stackrel{\infty}{-}$ & & & & $\underset{\sim}{ \pm}$ \\
\hline & 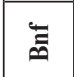 & & & $\cong$ & & & & & & & & $\cong$ \\
\hline & Е & $\begin{array}{l}3 \\
0 \\
f \\
f\end{array}$ & & 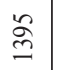 & & $\begin{array}{c}\text { mat } \\
\text { of }\end{array}$ & & & & & & $\underset{\infty}{\infty}$ \\
\hline & $\stackrel{\mathscr{c}}{\Sigma}$ & $\tilde{\Xi}$ & $\stackrel{\Delta}{\sim}$ & ओे & $\begin{array}{l}\stackrel{2}{2} \\
\approx\end{array}$ & & & & \& & $\stackrel{\Xi}{\beth}$ & & $\frac{n}{2}$ \\
\hline & 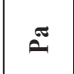 & 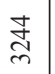 & $\approx$ & ๙ิ & $\begin{array}{l}0 \\
\infty \\
\infty\end{array}$ & $\frac{\vec{\infty}}{\vec{\infty}}$ & $\hat{\infty}$ & $\stackrel{\sim}{f}$ & & & & త్రి \\
\hline & 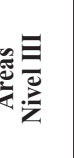 & 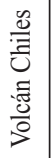 & 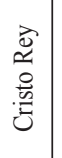 & 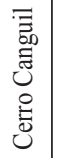 & 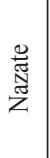 & 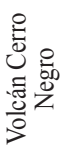 & 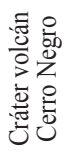 & 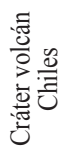 & 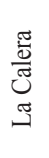 & 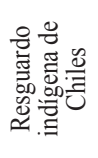 & 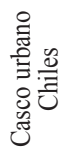 & \\
\hline & 兽 & & & & & & $\frac{\ddot{U}}{\tilde{Z}}$ & & & & & 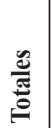 \\
\hline
\end{tabular}




\begin{tabular}{|c|c|c|c|c|c|c|c|c|c|c|c|c|c|c|c|c|c|c|c|c|}
\hline & 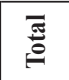 & 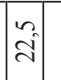 & & & & & & & & & & & & רี & $\Xi$ & $\vec{\sim}$ & I & 高 & : & 家 \\
\hline & $\approx$ & & & & & & & & & & & & & & & & : & & 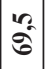 & $\mathbb{\pi}_{0}$ \\
\hline$\stackrel{m}{\bar{T}}$ & 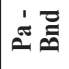 & & & & & & & & & & & & & & & & & & 0 & है \\
\hline 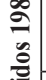 & 它言 & & & & & & & & & & & & & & & $\overrightarrow{\mathrm{i}}$ & कु & & $\begin{array}{l}+ \\
\dot{\alpha} \\
\dot{\alpha} \\
\end{array}$ & 酌 \\
\hline 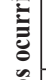 & 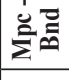 & & & & & & & & & & & & & & & & & & 0 & $\overbrace{0}^{n}$ \\
\hline | & 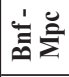 & & & & & & & & & & & & & & & & $\therefore$ & & $\therefore$ & $\frac{\tilde{2}}{0}$ \\
\hline 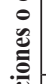 & 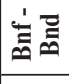 & & & & & & & & & & & & & & & & & \begin{tabular}{|l}
$n$ \\
0 \\
$o f$ \\
$m$ \\
$m$
\end{tabular} & $\begin{array}{l}0 \\
0 \\
0 \\
w \\
m\end{array}$ & 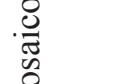 \\
\hline $\mid$ & 咅 & & & & & & & & & & & & & & & & & & 0 & $\sum_{0}^{\infty}$ \\
\hline . & 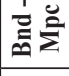 & & & & & & & & & & & & & & $\stackrel{m}{=}$ & & & & $=$ & $\sum$ \\
\hline & 它言 & 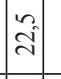 & & & & & & & & & & & & הi & $\begin{array}{l}2 \\
\stackrel{2}{2}\end{array}$ & & & & 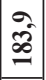 & 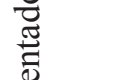 \\
\hline & 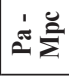 & & & & & & & & & & & & & & & & & & 0 & छ్ర్ర్ \\
\hline & تِّ & \begin{tabular}{|c|}
+ \\
aे \\
ते
\end{tabular} & 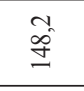 & के & \begin{tabular}{|l|}
$\widehat{\hat{A}}$ \\
0 \\
0
\end{tabular} & $\stackrel{\tilde{s}}{=}$ & 旾 & สี & $\stackrel{a}{s}$ & $\stackrel{2}{\Omega}$ & 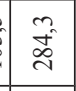 & 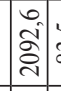 & 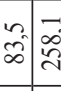 & $\begin{array}{c}n \\
0\end{array}$ & 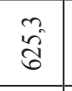 & \begin{tabular}{|c|}
$\hat{2}$ \\
$\hat{f}$
\end{tabular} & 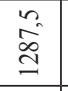 & $\stackrel{\infty}{a}$ & \begin{tabular}{|l|} 
\\
0 \\
0 \\
0 \\
0 \\
0
\end{tabular} & $\frac{\Phi}{\tilde{T}}$ \\
\hline & ש & & & & & & & & & & & $\stackrel{0}{\circ}$ & & $\stackrel{\forall}{=}$ & & & & & 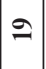 & $\stackrel{\Xi}{\varrho}$ \\
\hline & $\fallingdotseq$ & & & & & & & & & & & & & & & & & & 0 & \\
\hline 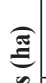 & so & & & & & & & & & & & & & & & & & & 0 & 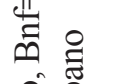 \\
\hline | & 离 & & $\stackrel{+}{n}$ & & & & $\begin{array}{c}\infty \\
\stackrel{\sigma}{q}\end{array}$ & & & & & $=$ & & 东 & $\underset{\infty}{m}$ & \begin{tabular}{|c|} 
\\
$\vdots$ \\
\end{tabular} & $\stackrel{\infty}{\infty}$ & $\stackrel{\infty}{\stackrel{\infty}{-}}$ & $\begin{array}{l}\infty \\
0 \\
0\end{array}$ & $\begin{array}{l}0 \\
0 \\
0 \\
0 \\
0\end{array}$ \\
\hline $\mid$ & 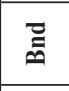 & $\begin{array}{l}\hat{\text { जे }} \\
\exists\end{array}$ & s. & & 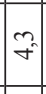 & & \begin{tabular}{l}
$\infty$ \\
\multirow{j}{*}{} \\
\end{tabular} & iี & e & $\infty$ & $\begin{array}{l}n \\
0 \\
0 \\
0 \\
0\end{array}$ & $\stackrel{0}{\circ}$ & $\overbrace{}^{2}$ & $\mid \begin{array}{l}n \\
\vdots \\
\hat{n} \\
\hat{n}\end{array}$ & \begin{tabular}{|l|} 
\\
0 \\
0 \\
0 \\
0
\end{tabular} & $\overrightarrow{\mathrm{c}}$ & $\hat{\stackrel{0}{R}}$ & 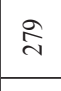 & $\mid \begin{array}{c}\infty \\
\substack{\infty \\
m}\end{array}$ & 窇: \\
\hline & $\stackrel{0}{\grave{z}}$ & & $\vec{m}$ & & 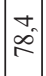 & & $\stackrel{m}{7}$ & & & ? & $\stackrel{0}{-}$ & $\vec{\sim}$ & \begin{tabular}{l|l}
$\stackrel{n}{n}$ \\
\hdashline
\end{tabular} & $\overrightarrow{=}$ & $\vec{a}$ & & $\hat{\vec{i}}$ & $\overrightarrow{\not ే}$ & $\mathbb{d}$ & $\begin{array}{l}\tilde{0} \\
\varrho\end{array}$ \\
\hline & $\approx$ & \begin{tabular}{|c|c|}
$\mid$ \\
$\vdots$ \\
2
\end{tabular} & & $\hat{q}$ & & $\stackrel{\hat{\varrho}}{=}$ & 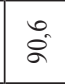 & 8 & 品 & & $\begin{array}{l}\stackrel{\mathcal{I}}{ \pm} \\
\end{array}$ & 言 & ت. & 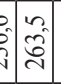 & $\overrightarrow{\mathrm{n}}$ & $\stackrel{m}{2}$ & 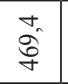 & बें & 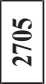 & 音. \\
\hline & 恶 & 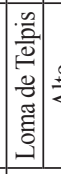 & 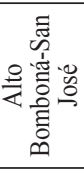 & 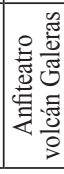 & 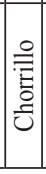 & 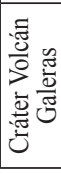 & 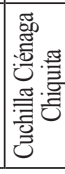 & 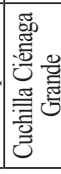 & 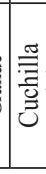 & 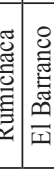 & 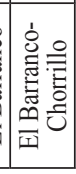 & 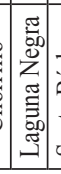 & 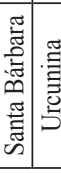 & $\frac{a}{2}$ & 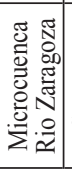 & 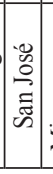 & 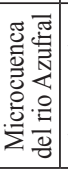 & 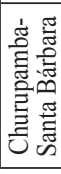 & & 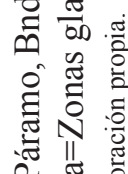 \\
\hline & 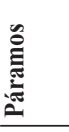 & & & & & & & & & 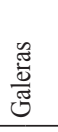 & & & & & & & & & 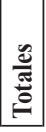 & 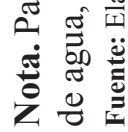 \\
\hline
\end{tabular}


Tabla 3. Transformaciones de las Áreas de paisaje Nivel III, páramo de Paja Blanca

\begin{tabular}{|c|c|c|c|c|c|c|c|c|c|c|c|c|}
\hline \multirow{2}{*}{ Áreas Nivel III } & \multicolumn{5}{|c|}{ Persistencias (ha) } & \multicolumn{6}{|c|}{$\begin{array}{c}\text { Transformaciones o cambios ocurridos } \\
1984-2013 \\
\end{array}$} & \multirow{2}{*}{ Total } \\
\hline & $\mathrm{Pa}$ & Mpc & Bnd & Bnf & Total & $\begin{array}{l}\text { Bnd - } \\
\text { Mpc }\end{array}$ & $\begin{array}{l}\text { Bnf - } \\
\text { Bnd }\end{array}$ & $\begin{array}{l}\text { Bnf - } \\
\text { Mpc }\end{array}$ & $\begin{array}{c}\text { Bnf - } \\
\text { Pa }\end{array}$ & $\begin{array}{c}\text { Mpc - } \\
\text { Bnf }\end{array}$ & $\begin{array}{l}\mathrm{Pa}- \\
\mathrm{Bnf}\end{array}$ & \\
\hline Loma Paja Blanca & 308,5 & & & 137,1 & 445,6 & & & & 32 & 5,3 & 42,2 & 79,5 \\
\hline Cerro Campana & 68,1 & & & & 68,1 & & & & & & & \\
\hline Cerro las cruces & 17,3 & & & 14,1 & 31,4 & & & & & & & \\
\hline Las Guacas & & 96,9 & & & 96,9 & & & & & & & \\
\hline Loma Imbula Grande & 27,6 & & & 29,5 & 57,1 & & & & & & & \\
\hline $\begin{array}{l}\text { San José de } \\
\text { Chillanquer }\end{array}$ & & 15,2 & & & 15,2 & & & & & & & \\
\hline Loma La Gorgona & 23 & & 1,1 & 36 & 60,1 & & & & & & & \\
\hline Pilispí & & 11,4 & & & 11,4 & & & & & & & \\
\hline Santo Domingo & & 20,9 & & & 20,9 & & & & & & & \\
\hline $\begin{array}{l}\text { Villa del Sur, } \\
\text { Gavilanes, Los Monos, } \\
\text { La Campana }\end{array}$ & 2,1 & 434 & & & 435,8 & & & 86,6 & & & & 86,6 \\
\hline San José & & 13,7 & & & 13,7 & & & & & 1,2 & & 1,2 \\
\hline Chires Mirador & & 50 & & 4,3 & 54,3 & & & 6,7 & & & & 6,7 \\
\hline Imbula Grande & 51,2 & 51 & & 165,1 & 267,3 & & & 26,9 & & 56,4 & & 83,3 \\
\hline El Mirador & & 32,1 & & & 32,1 & & & 8 & & & & 8 \\
\hline $\begin{array}{l}\text { El Común, Imbula } \\
\text { Chico }\end{array}$ & & 191 & & & 191,4 & & & 12,1 & & & & 12,1 \\
\hline $\begin{array}{l}\text { Imbula Grande, } \\
\text { Chorrera Negra }\end{array}$ & & 67,5 & & 3,4 & 70,9 & 1,1 & & 13,2 & & & & 14,3 \\
\hline Chorrera Negra & 135,6 & 61,6 & 16 & 163,4 & 376,6 & 2,7 & 12,3 & 26,9 & & 5,5 & & 47,4 \\
\hline Dos caminos & & 13,7 & & & 13,7 & & & 7,2 & & & & 7,2 \\
\hline Loma Redonda & & & & 35,5 & 35,5 & & & 12,4 & & & & 12,4 \\
\hline Loma El Caliente & 10,4 & 10,8 & & 87,9 & 109,1 & & & 3,2 & & & 6,5 & 9,7 \\
\hline Loma El Pailón & & 12,4 & & 27,3 & 39,7 & & & & & 17,3 & & 17,3 \\
\hline Loma El Mirador & & & & 48,8 & 48,8 & & & & & & 5,6 & 5,6 \\
\hline El Carmen, El Común & & & & 9,4 & 9,4 & & & 85,5 & & & & 85,5 \\
\hline $\begin{array}{l}\text { El Carmen, Chorrera } \\
\text { Negra, Los Cedros }\end{array}$ & 70,8 & 7,2 & & 225,4 & 303,4 & & & 21,9 & & & 9,8 & 31,7 \\
\hline $\begin{array}{l}\text { San José de } \\
\text { Chillanquer, Casa } \\
\text { Fría, Chires mirador, } \\
\text { Piacun, Imbula Chico }\end{array}$ & 19,3 & 8,5 & & 193,8 & 221,6 & & & 15,9 & 1,2 & 90,5 & & 108 \\
\hline $\begin{array}{l}\text { El Común, Villa del } \\
\text { Sur }\end{array}$ & 59,5 & & & 166,1 & 225,6 & & & 6,2 & & 26,3 & 6,2 & 38,7 \\
\hline La Campana & 34,4 & 49,9 & 1,3 & 114,4 & 200 & & & & & & 5 & 5 \\
\hline El Gualte & 28,9 & 77,6 & & 84,5 & 191 & & & 12,6 & & 26,3 & & 38,9 \\
\hline Villanueva & & 101 & & 34,8 & 136,1 & & & & & 5,3 & & 5,3 \\
\hline Maramba & 4,4 & 1,6 & & 50,4 & 56,4 & & & & & & 1,9 & 1,9 \\
\hline Totales & 861 & 1328 & 18,4 & 1631 & 3839,1 & 3,8 & 12,3 & 345,3 & 33,2 & 234,1 & 77,2 & 706 \\
\hline
\end{tabular}

Nota. $\mathrm{Pa}=\mathrm{Pá}$ amo, $\mathrm{Bnd}=\mathrm{Bosque}$ natural denso, $\mathrm{Bnf}=\mathrm{B}$ osque natural fragmentado, $\mathrm{Mpc}=$ Mosaico de pastos y cultivos, $\mathrm{Ca}=\mathrm{Cuerpos}$ de agua, $\mathrm{Za}=\mathrm{Z}$ onas glaciares, Tuc=Tejido urbano

Fuente: Elaboración propia. 


\subsection{Simulación de los paisajes}

Los resultados de las simulaciones (Tabla 4), muestran que, en el páramo de Chiles, el área de paisaje denominada "Cerro Cangüil" es la más propensa a experimentar cambios, especialmente transformaciones de coberturas de páramo y bosque natural denso a mosaico de pasto y cultivos.

Tabla 4. Cambios de coberturas proyectados para el año 2042

\begin{tabular}{|c|c|c|c|c|c|c|c|c|c|c|c|c|c|}
\hline Páramos & $\begin{array}{c}\text { Áreas Nivel } \\
\text { III }\end{array}$ & $\begin{array}{l}\text { Pa - } \\
\text { Mpc }\end{array}$ & \begin{tabular}{|c|} 
Bnd - \\
Bnf
\end{tabular} & $\begin{array}{l}\text { Bnd - } \\
\text { Mpc }\end{array}$ & $\begin{array}{c}\text { Bnd - } \\
\text { Pa }\end{array}$ & $\begin{array}{c}\text { Bnf - } \\
\text { Bnd }\end{array}$ & $\begin{array}{l}\text { Bnf - } \\
\text { Mpc }\end{array}$ & $\begin{array}{c}\text { Bnf - } \\
\text { Pa }\end{array}$ & $\begin{array}{l}\text { Mpc - } \\
\text { Bnd }\end{array}$ & $\begin{array}{c}\text { Mpc - } \\
\text { Bnf }\end{array}$ & $\begin{array}{l}\text { Pa - } \\
\text { Bnd }\end{array}$ & $\begin{array}{l}\text { Pa - } \\
\text { Bnf }\end{array}$ & Total \\
\hline \multirow{4}{*}{ Chiles } & Volcán Chiles & & & & & & & & & & 86,2 & & 86,2 \\
\hline & Cristo Rey & & & & & & & & & & 12,5 & & 12,5 \\
\hline & Cerro Cangüil & 109,7 & 70,6 & 122,3 & 23,9 & 83,9 & & & 20 & & & 4,1 & 435 \\
\hline & Nazate & & & & & & & & & & 17 & & 17 \\
\hline \multicolumn{2}{|l|}{ Totales } & 109,7 & 70,6 & 122,3 & 23,9 & 83,9 & $\mathbf{0}$ & $\mathbf{0}$ & 20 & $\mathbf{0}$ & 115,7 & 4,1 & 550 \\
\hline \multirow{13}{*}{ Galeras } & \begin{tabular}{|l} 
Anfiteatro \\
Volcán \\
Galeras
\end{tabular} & & & & & & & & & & & 16,5 & 16,5 \\
\hline & Chorrillo & & & & & & & & & 2 & & & 2 \\
\hline & \begin{tabular}{l|} 
Churupamba- \\
Santa Bárbara
\end{tabular} & & 30,4 & & & & & & & 1 & & & 31,4 \\
\hline & \begin{tabular}{|l} 
Cuchilla \\
Ciénaga \\
Chiquita
\end{tabular} & & & & & & & & & & & 5,2 & 5,2 \\
\hline & $\begin{array}{l}\text { El Barranco } \\
\text { Chorrillo }\end{array}$ & & & & & & & & & & & 1,2 & 1,2 \\
\hline & \begin{tabular}{|l|} 
Laguna Negra \\
\end{tabular} & & & & & 44,9 & 1,2 & & & 10,9 & & 7,2 & 64,2 \\
\hline & \begin{tabular}{|l|}
$\begin{array}{l}\text { Loma de } \\
\text { Telpis }\end{array}$ \\
\end{tabular} & & & & & 21,2 & & & & & & & 21,2 \\
\hline & $\begin{array}{l}\text { Microcuenca } \\
\text { del rio Azufral }\end{array}$ & & 111,9 & & & 89.9 & & & & & & & 112 \\
\hline & $\begin{array}{l}\text { Microcuenca } \\
\text { Rio Zaragoza }\end{array}$ & & 41,7 & & & & 3,4 & & & & & & 45,1 \\
\hline & San José & & & & & 69 & & & & & & & 69 \\
\hline & Santa Bárbara & & & & & & & & & 5,8 & & & 5,8 \\
\hline & Telpis & & & 1,1 & & 22,7 & & & & & & & 23,8 \\
\hline & Urcunina & & & & & & & & & 8,9 & & 1 & 9,9 \\
\hline \multicolumn{2}{|l|}{ Totales } & $\mathbf{0}$ & 184 & 1,1 & 0 & 157,8 & 4,6 & $\mathbf{0}$ & $\mathbf{0}$ & 28,6 & $\mathbf{0}$ & 31,1 & 407 \\
\hline
\end{tabular}

Nota. $\mathrm{Pa}=$ Páramo, Bnd=Bosque natural denso, $\mathrm{Bnf}=$ Bosque natural fragmentado, $\mathrm{Mpc}=$ Mosaico de pastos $\mathrm{y}$ cultivos, $\mathrm{Ca}=$ Cuerpos de agua, $\mathrm{Za}=$ Zonas glaciares, Tuc $=$ Tejido urbano $\mathrm{Pa}=$ Páramo, Bnd=Bosque natural denso, Bnf=Bosque natural fragmentado, $\mathrm{Mpc}=$ Mosaico de pastos y cultivos.

Fuente: Elaboración propia. 
En Galeras podemos observar áreas de paisaje en donde se experimentarían ganancias positivas de coberturas (bosque natural fragmentado a bosque natural denso) como el caso de Laguna Negra y Microcuenca del río Azufral, pero también pérdidas (bosque natural denso a bosque natural fragmentado) como en los paisajes Churupamba-Santa Bárbara, Microcuenca río Zaragoza y también en algunos sectores del paisaje Microcuenca del río Azufral. De igual manera en Paja Blanca, el modelo establece que pueden existir pérdidas y ganancias de bosque natural fragmentado, tal como sucede en las áreas de paisaje El Carmen, Chorrera Negra, Los Cedros, El Gualte, La Campana, Loma Paja Blanca, Las Guacas, El Carmen-El Común, San José de Chillanquer-Casa Fría-Chires mirador-Piacun, Imbula Chico (siendo más crítica en esta última).

\subsection{Cualificación}

Como ejemplo de aplicabilidad y calibración de este método, se escogieron tres paisajes de Nivel III: Volcán Chiles, Laguna Negra y Loma Paja Blanca, que corresponden a paisajes de los páramos Chiles, Galeras y Paja Blanca respec- tivamente. La valoración objetiva permitió establecer que estos paisajes poseen un importante valor ecológico ya que albergan una inmensa riqueza tanto de flora como fauna típica de los ambientes paramunos. Asimismo, poseen unos valores productivos actuales como el ecoturismo y la investigación.

Los tres ámbitos estudiados presentan una gran riqueza mitológica, espiritual y simbólica, a través de su historia han constituido la fuente de muchas creencias arraigadas pues son parte de la cultura de quienes habitan en sus áreas de influencia. El principal valor de uso social que tienen las tres áreas de paisaje es la producción de agua a través de diversos nacimientos que conforman riachuelos, que a su vez abastecen acueductos y sistemas de riego de las cabeceras municipales y también veredales.

El proceso de valoración directa subjetiva también se aplicó para las áreas de paisaje Volcán Chiles, Laguna Negra y Loma Paja Blanca (Figura 2). 


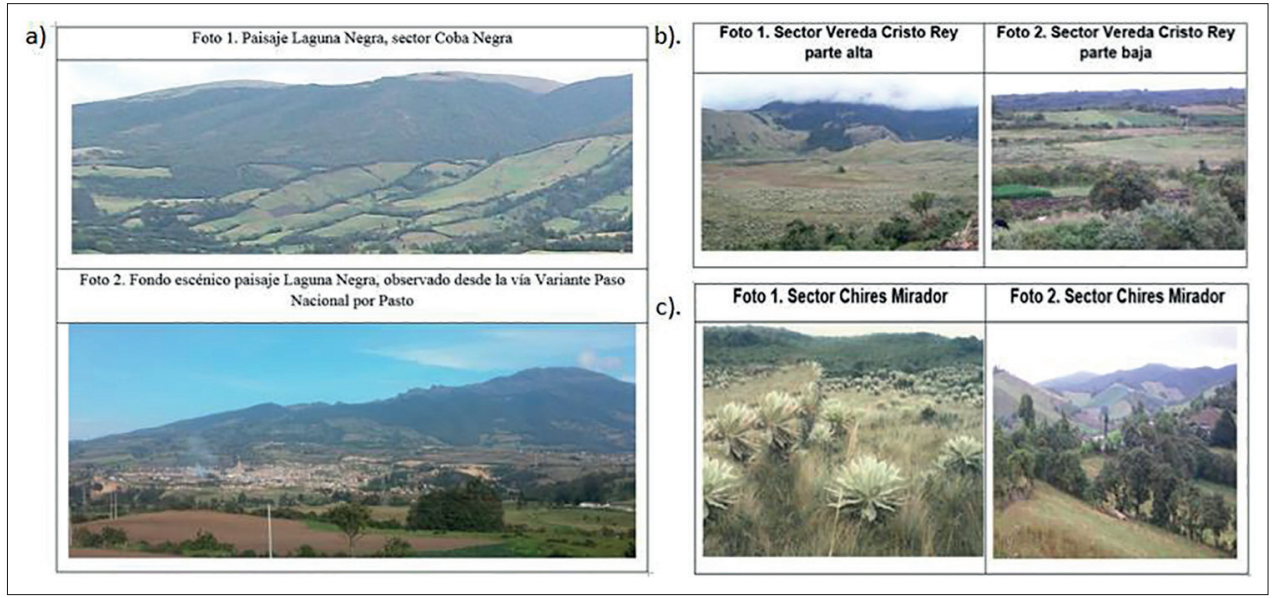

Figura 2. Áreas de paisaje de Nivel III: (a) Laguna Negra (Páramo de Galeras), (b) Volcán Chiles (Páramo de Chiles) y (c) Loma Paja Blanca (Páramo de Paja Blanca). Fuente: Elaboración propia.

Al ser sometidos estos paisajes a la valoración con base a los adjetivos que se muestran en la Tabla 5, el promedio general del Área de paisaje Loma Paja Blanca fue de 7.0 en la escala de Fines, lo que significa un puesto en la categoría de "Distinguido". Los resultados de la valoración del paisaje Volcán Chiles permiten determinar que dicho paisaje obtuvo un promedio total de 8.4 en la escala de Fines, que lo clasifica como un paisaje "Fantástico". En promedio para el paisaje Laguna Negra, se obtuvo un promedio general de 10 en la escala de Fines, lo que lo ubica, también, en la categoría "Fantástico". Dicha categoría representa para el fondo escénico del paisaje un valor muy importante, pues se encuentra enriquecido con otros componentes urbanos y agropecuarios. Asimismo, las comunidades dan más valor estético a aquellos paisajes donde los fondos escénicos corresponden a grandes estructuras geomorfológicas como son los volcanes, por ello, los paisajes Laguna Negra y Volcán Chiles fueron catalogados como fantásticos. En Paja Blanca, por el contrario, donde no se aprecia una estructura volcánica bien definida, la calificación fue menor. 
Tabla 5. Lista de adjetivos jerarquizados y su correlación con la escala universal de valores

\begin{tabular}{|c|c|c|c|c|c|c|c|}
\hline Adjetivos & Valor & Categoría & Valor & Adjetivos & Valor & Categorías & Valor \\
\hline 1. Insoportable & 0 & \multirow{5}{*}{ Feo } & \multirow{5}{*}{$0-1$} & 6. Triste & 1,1 & \multirow{5}{*}{ Sin interés } & \multirow{5}{*}{$1,1-2$} \\
\hline 2. Horrible & 0,25 & & & 7. Pobre & 1,25 & & \\
\hline 3. Desagradable & 0,5 & & & 8. Frío & 1,5 & & \\
\hline 4. Pésimo & 0,75 & & & 9. Monótono & 1,75 & & \\
\hline 5. Feo & 1 & & & 10. Sin interés & 2 & & \\
\hline 11. Común & 2,1 & \multirow{5}{*}{ Agradable } & \multirow{5}{*}{$2,1-4$} & 16. Interesante & 4,1 & \multirow{5}{*}{ Distinguido } & \multirow{5}{*}{$4,1-8$} \\
\hline 12. Sencillo & 2,5 & & & 17. Grato & 5 & & \\
\hline 13. Pasable & 3 & & & 19. Conservado & 7 & & \\
\hline 14. Regular & 3,5 & & & \multirow{2}{*}{ 20. Singular } & \multirow{2}{*}{8} & & \\
\hline 15. Aceptable & 4 & & & & & & \\
\hline 21. Variado & 8,1 & \multirow{5}{*}{ Fantástico } & \multirow{5}{*}{$8,1-16$} & 26. Estupendo & 16,1 & \multirow{5}{*}{ Espectacular } & \multirow{5}{*}{$16,1-32$} \\
\hline 22. Estimulante & 10 & & & 27. Soberbio & 20 & & \\
\hline 23. Bonito & 12 & & & 28. Maravilloso & 24 & & \\
\hline 24. Hermoso & 14 & & & 29. Fantástico & 28 & & \\
\hline 25. Precioso & 16 & & & 30. Espectacular & 32 & & \\
\hline
\end{tabular}

Fuente: Adaptado de Muñoz-Pedreros et al. (1993).

En el Área de paisaje Loma Paja Blanca, las pruebas de varianza no mostraron significación estadística $(p>0.05)$ entre los valores de valoración del paisaje de acuerdo al sexo, ocupación y edad. Es decir, estos aspectos no inciden en la percepción y valoración del paisaje. Para la primera fotografía del área de paisaje Volcán Chiles, se presentaron diferencias estadísticas altamente significativas $(\mathrm{P}<0,05)$ entre las edades y las valoraciones otorgadas. Por el contrario, la ocupación y el sexo no inciden en el tipo de calificación asignada. En el paisaje de la segunda imagen de este mismo paisaje, no se presen- taron diferencias entre los diferentes rangos correspondientes a sexo, edad y ocupación. En el paisaje Laguna Negra tampoco se identificaron diferencias estadísticas entre edad, ocupación y sexo con respecto al tipo de valoración dada.

Con respecto a lo que las comunidades desean de estos paisajes, la encuesta indicó que en el paisaje Laguna Negra, el $40 \%$ desea un paisaje mejorado; en el paisaje Volcán Chiles, el $60 \%$ prefiere que este paisaje se conserve; y en el paisaje Loma Paja Blanca el 47\% desea mecanismos efectivos de protección. 


\subsection{Políticas (objetivos de calidad} paisajística)

Como resultado final de esta metodología, en la Tabla 6 se observa una matriz que sintetiza cada área de paisaje de Nivel III en sus principales aspectos fisicobióticos, transformaciones ocurridas, simulaciones o tendencias futuras, y sus principales valores. Por último, también se observan unas recomendaciones de actuación o intervención paisajística acorde a las características anteriores, y sobre todo a las aspiraciones de las poblaciones en lo que concierne a las características paisajísticas de su entorno.
El método propuesto, con base a las directrices de la Iniciativa Latinoamericana del Paisaje, sugiere que los resultados finales se integren como políticas de paisaje (con su debida importancia) a políticas públicas sectoriales (infraestructura y movilidad, producción, explotación de recursos, energías renovables, salud, turismo, urbanismo y vivienda). Los poderes públicos y privados, así como los agentes sociales y la sociedad en general, han de velar por su cumplimiento $y$ puesta en práctica. 


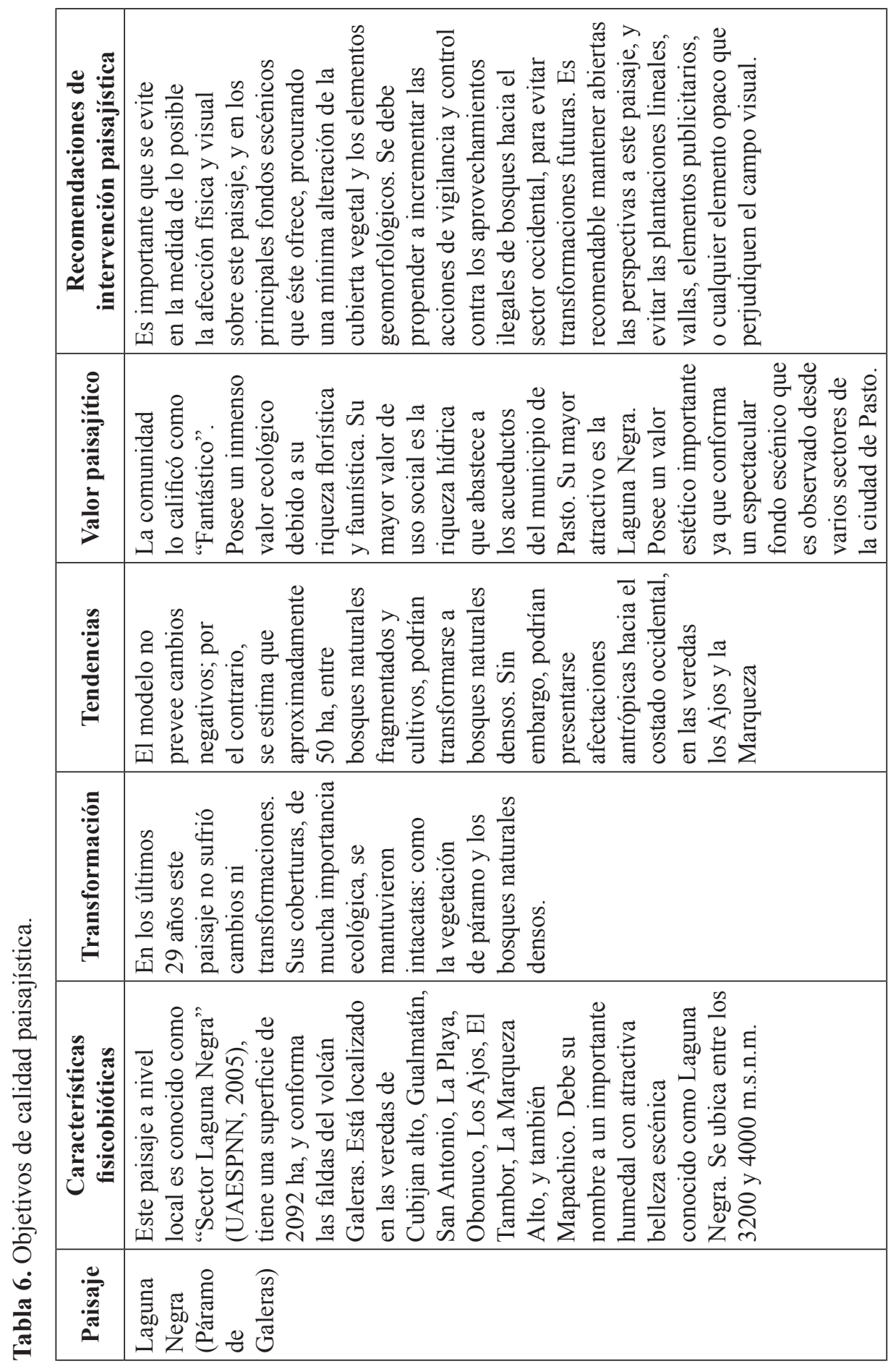




\begin{tabular}{|c|c|}
\hline 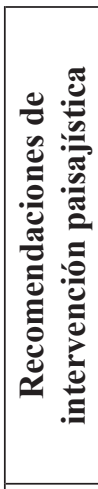 & 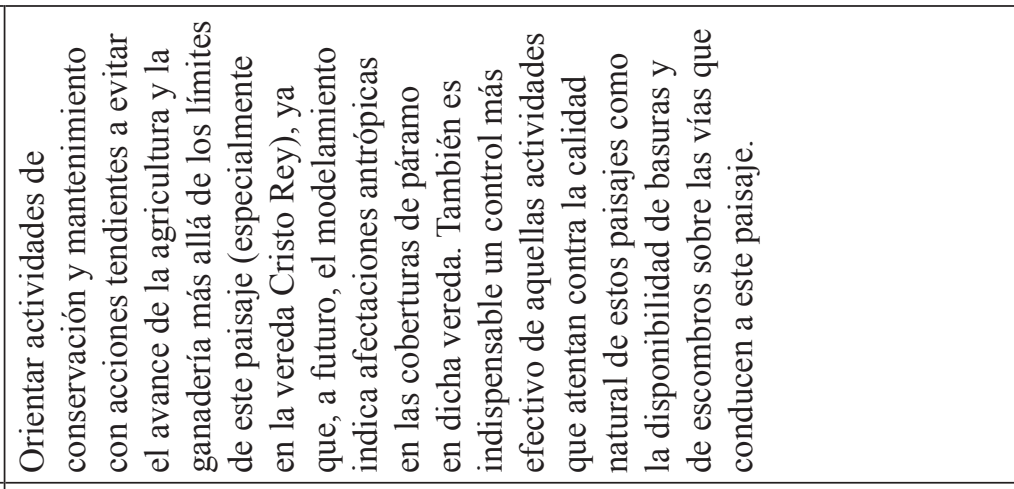 \\
\hline 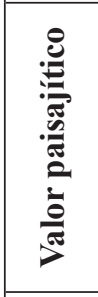 & 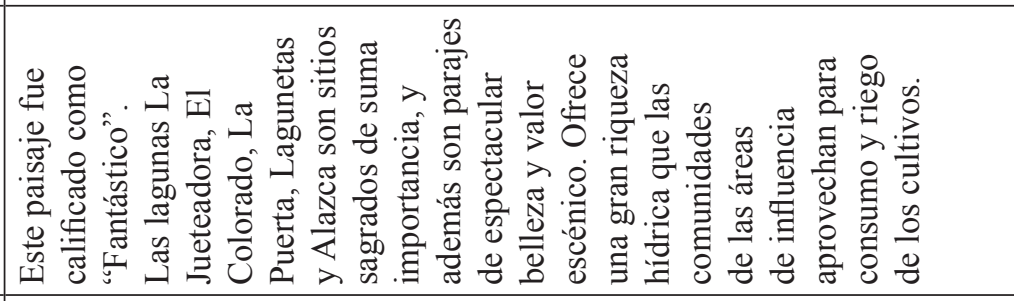 \\
\hline 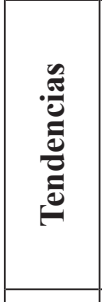 & 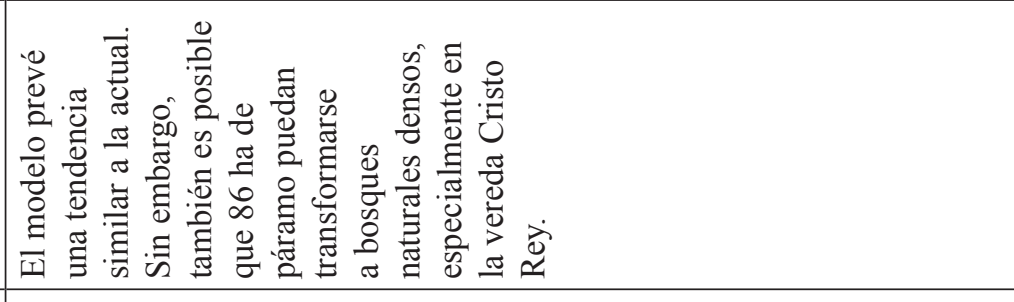 \\
\hline 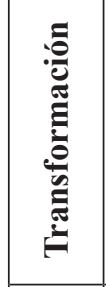 & 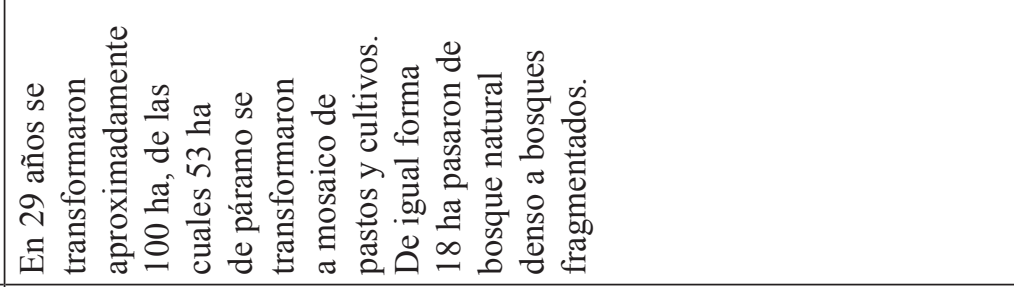 \\
\hline 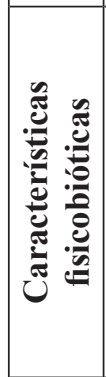 & 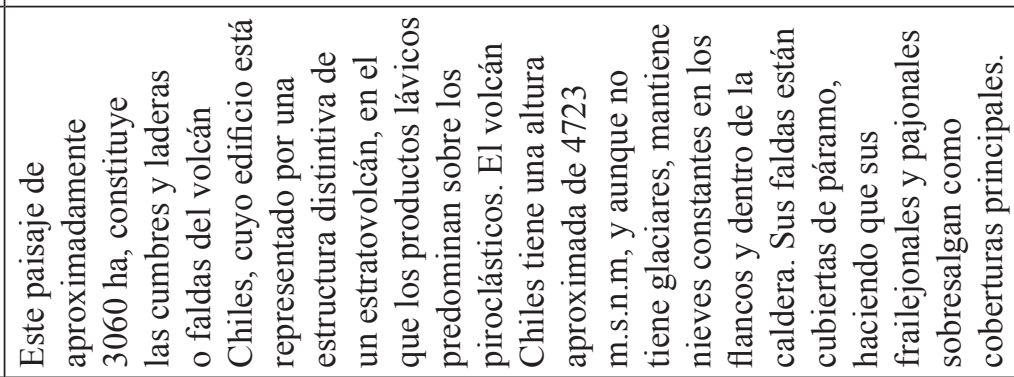 \\
\hline 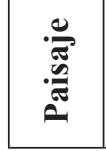 & 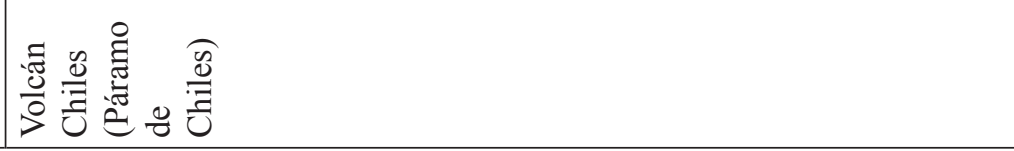 \\
\hline
\end{tabular}




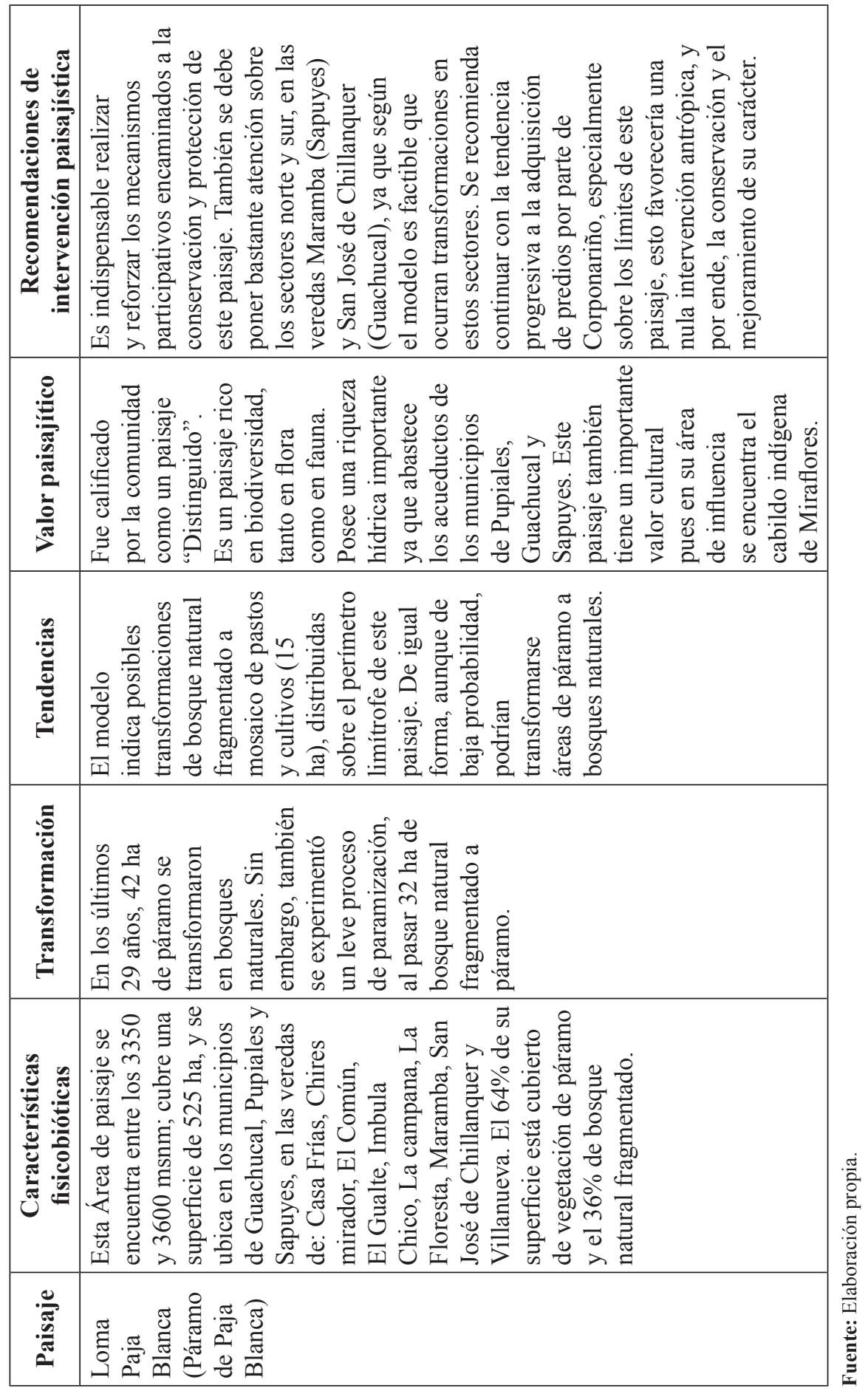




\section{Conclusiones}

La clasificación o sectorización paisajística en áreas y tipos de paisaje, permite un desglose iterativo interesante del paisaje, que obliga además al investigador a buscar nombres apropiados según sus toponimias o nombres dados por la población, lo cual permite que se refuerce el arraigo y el vínculo territorial de los paisajes.

La inclusión de las etapas de transformación y simulación, a través de un análisis multitemporal junto con un estudio de sus principales causas, así como la simulación prospectiva mediante métodos de redes neuronales, fueron complementos técnicos que no han sido tenidos en cuenta en otras propuestas similares, pero que resultan ser refuerzos importantes e interesantes en el proceso de generar un instrumento de gestión del paisaje en el marco de la Iniciativa Latinoamericana del Paisaje (LALI).

La aplicación de este método pudo constatar que los paisajes de los páramos Chiles, Galeras y Paja Blanca han sufrido transformaciones a causa de factores antrópicos, presentándose de manera crítica sobre todo en Paja Blanca y Chiles. Asimismo, las simulaciones hechas indican que de continuar con las tendencias actuales el comportamiento puede ser el mismo para los próximos 30 años.

El método propuesto delimitó un total de 64 áreas de paisaje de Nivel III, de las cuales la mayoría (36 unidades) corresponden a Paja Blanca. Esto se debe a que las comunidades del páramo reconocen con toponimias específicas varios elementos del paisaje como cerros y lomas de su importancia, lo que permitió una sectorización paisajística mucho más amplia que en los otros ámbitos.

No se encontraron diferencias estadísticas entre el sexo, la edad y la ocupación, con respecto al tipo de valoración perceptiva visual que las comunidades dieron a las áreas de paisaje. Sin embargo, entre los ámbitos estudiados se pudo establecer que los paisajes donde se aprecia como fondos escénicos las estructuras volcánicas, presentan más valoración visual que aquellas que no la tienen, como en el caso del páramo de Paja Blanca.

La propuesta metodológica elaborada en esta investigación permite su aplicabilidad en distintos paisajes, y a diferentes escalas para la implementación de la Iniciativa Latinoamericana del Paisaje. 


\section{Referencias}

Aramburu, M. P., et al. (2006). Guía para la elaboración de estudios del medio físico (3a. Edición). Madrid: Ministerio de Medio Ambiente.

Bonilla, A. (1985). Situación ambiental de Costa Rica. San José: Ministerio de Cultura, Juventud y Deportes.

Brown, T. and Daniel, T. (1986). Predicting Scenic Beauty of Timber Stands. Forest Science, (32), 471-487.

Castleman, K. (1996). Digital Imagine Processing. Upper Saddle River, NJ: Prentice Hall.

Consejo De Europa. (2000). Convenio Europeo del Paisaje. Florencia. Recuperado de http:// www.uv.es/masterpatrimonio/legislacion/convenio_euro_protec_2000.pdf

Craik, K. (1975). Individual Variations in Landscapes Description. In E. Zube, R. Brush and J. Fabos. (Eds.), Landscape Assessment, Values Perceptions and Resources (pp. 130-150). Stroudsburg, PA: Dowden, Hutchinson \& Ross Inc.

Eastman, J. R. (2006). IDRISI 15 Andes. Guide to GIS and Image Processing. Worchester, MA: Clark University.

Federación Internacional de Arquitectos Paisajistas. (2012). Iniciativa Latinoamericana del Paisaje (LALI). Medellín. Recuperado de http://iflaonline.org/wp-content/ uploads/2014/12/120910-LALI_EN_Final.pdf

Fines, K. (1968). Landscape Evaluation: A research Project in East Sussex. Regional Studies, (2), 41-55.

Glasser, D. and Strauss, A. (1967). The Discovery of Grounded Theory: Strategies for Qualitative Research. New York: Aldine Publishing Company.

Gómez-Zotano, J. (2004). El papel de los espacios montañosos como traspaís del litoral mediterráneo Andaluz: el caso de Sierra Bermeja (provincia de Málaga). Granada: Universidad de Granada.

Gómez, J. y Riesco, P. (2010). Marco Conceptual y Metodológico para los Paisajes españoles. Aplicación a Tres Escalas Espaciales. Sevilla: Consejería de Obras Públicas y Vivienda.

Hartshorn, G. (1983). Costa Rica perfil ambiental. San José: Trejos.

Instituto de Investigación de Recursos Biológicos Alexander Von Humboldt, IAvH. (2009). Estudio sobre el estado actual del páramo de Chiles (Convenio Marco de Cooperación No. 07-129). 
Isasi, N. y Galván, M. (2004). Redes Neuronales Artificiales: un enfoque práctico. Madrid: Pearson Education, S.A.

Mallarach, J. (2008). Valores Culturales y Espirituales de los Paisajes Protegidos (Volumen 2 de la serie Valores de los Paisajes Terrestres y Marinos Protegidos). Sant Joan les Fonts: UICN; GTZ; Obra Social de Caixa Catalunya.

Muñoz-Pedreros, A., Badilla, A. y Rivas, H. (1993). Evaluación del paisaje en un humedal del sur de Chile: el caso del río Valdivia (X Región). Revista Chilena de Historia Natural, (66), 403-118.

Muñoz-Pedreros, A., Moncada, J. y Larraín, A. (2000). Variabilidad de la percepción del recurso paisaje en el sur de Chile. Revista Chilena de Historia Natural, (73), 729-738.

Paquet, J. and Bélanger, L. (1997). Public Acceptability Thresholds of Clearcutting to Maintain Visual Quality of Boreal Balsam for Landscapes. Forest Science, (43), 46-55

Pérez, S. y Protti, F. (1978). Comportamiento del sector forestal durante el período 1950-1977. San José: Oficina de Planificación Sectorial Agropecuaria.

SAP, Sociedad Colombiana de Arquitectos Paisajistas. (2010). Carta Colombiana del Paisaje. Recuperado de http://www.sapcolombia.org/pdf/La_CartaColombiana_del_Paisaje_2010. pdf

Unidad Administrativa Especial del Sistema de Parques Nacionales Naturales, UAESPNN. (2005). Plan de manejo 2006-2010 Santuario de Flora y Fauna Galeras. 228 p. Recuperado de http://www.parquesnacionales.gov.co/portal/wp-content/uploads/2013/12/Galeras.pdf

Recepción: 8 de junio de 2016

Evaluación: 25 de octubre de 2016

Aprobación: 15 de noviembre de 2016 